\title{
THE VALUE OF PERIOPERATIVE INTRAOCULAR PRESSURE MEASUREMENT IN TRABECULECTOMY AS A PREDICTOR OF THE EARLY POST-OPERATIVE COURSE
}

\author{
J. SUHARWARDY ${ }^{1}$ and P. BARANYOVITS ${ }^{2}$ \\ Kettering
}

\begin{abstract}
SUMMARY
Purpose: The purpose of the study was to assess the value of perioperative intraocular pressure (IOP) measurement in trabeculectomy as a predictor of drainage and related complications in the early postoperative period.

Methods: A prospective study was undertaken of $\mathbf{4 2}$ eyes (39 patients) followed up after trabeculectomy for the first post-operative month.

Results: Analysis of the change in IOP in the first postoperative month showed that at 1 month the pressure in all cases tended to similar values irrespective of the mean perioperative IOP. Early shallowing of the anterior chamber was, however, associated with a significantly lower perioperative IOP, although there was no significant difference in IOP at 1 month in these cases.

Conclusions: The perioperative IOP appears to be effective in predicting anterior chamber shallowing in the first post-operative month with good sensitivity and specificity, but has little value as a predictor of the IOP at 1 month.
\end{abstract}

Flat or shallow anterior chambers with persistent hypotony were complications frequently seen in the full-thickness filtering procedures and led to the development of trabeculectomy in the late 1960s. ${ }^{1.2}$ Whilst trabeculectomy certainly appears to have fewer of these complications there is still a problem of unpredictable drainage in the immediate postoperative period. ${ }^{3,4}$

Insufficient drainage, usually due to a tight scleral flap or occlusion of the trabeculectomy site by the iris

From: ${ }^{1}$ University Department of Ophthalmology, Manchester Royal Eye Hospital, Oxford Road, Manchester M13 9WH, UK; ${ }^{2}$ Eye Department, Kettering General Hospital, Kettering, UK.

Correspondence to: Mr P. Baranyovits, Eye Department, Kettering General Hospital, Rothwell Road, Kettering NN16 8UZ, UK. lens diaphragm, may resolve spontaneously, require intermittent massage or may remain high requiring laser, medical or further surgical treatment.

Shallowing of the anterior chamber due to overfiltration occurs after many cases of trabeculectomy although re-formation usually occurs by 14 days., Whilst a flat anterior chamber with corneal-lens touch requires more aggressive management, the majority of shallow chambers due to excessive filtration resolve with conservative treatment. ${ }^{7.8}$

In this study we have attempted to show whether it is possible to predict the early post-operative course following trabeculectomy from the intraocular pressure (IOP) measured at the time of surgery. If this is the case it may then be possible to modify the procedure by increasing or decreasing drainage through the trabeculectomy site.

\section{MATERIALS AND METHODS}

This was a prospective study and from the commencement of the study all patients undergoing trabeculectomy were included with no exclusions. Forty-two trabeculectomies were performed on 39 patients by three different surgeons following the same procedure. Thirty-seven eyes had chronic open angle glaucoma, 5 had angle closure glaucoma and 5 were having repeat trabeculectomies. All the operations were carried out with the patient under general anaesthetic.

A standard trabeculectomy was performed on all cases. A fornix-based conjunctival flap was fashioned with a $5 \times 5 \mathrm{~mm}$ scleral flap and $3 \times 2 \mathrm{~mm}$ block excision. Prior to resuturing the conjunctiva the chamber was re-formed using the paracentesis site and balanced. salt was injected until fluid could be seen just escaping from under the scleral flap. The IOP was then measured using a Perkins hand-held tonometer. The measurement was repeated 5 minutes

Eye (1997) 11, 109-112 C 1997 Royal College of Ophthalmologists 
Table I. Mean (range) IOP levels ( $\mathrm{mmHg}$ ) at various times for the sample as a whole and subdivided into groups 1 and 2

\begin{tabular}{lcccc}
\hline & \multicolumn{4}{c}{ IOP (mmHg) } \\
\cline { 2 - 5 } & Perioperative & Post-op. day 1 & Post-op. day 7 & Post-op. day 30 \\
\hline Total sample (42 cases) & $5.2(0-16)$ & $7.9(0-50)$ & $9.7(3-22)$ & $14.7(6-30)$ \\
Group 1 (23 cases) & $2.5(0-5)$ & $3.7(0-12)$ & $7(4-16)$ & $13.5(6-22)$ \\
Group 2 (19 cases) & $8.5(5.5-16)$ & $12.9(2-50)$ & $13.1(3-22)$ & $16.3(6-30)$ \\
\hline
\end{tabular}

later, after which the conjunctiva was resutured and the anaesthetic reversed.

Patients were then seen at 1 day, 1 week and 1 month post-operatively for a full ophthalmic examination. IOP was measured, the drainage blebs were all checked for evidence of a leak and the anterior chamber (AC) depth was assessed and graded. Chamber depth was graded as follows: group a, AC flat with lens-corneal touch; group b, AC flat with iris-corneal touch; group c, AC shallow but formed; group d, AC deep.

The mean IOPs were compared using non-parametric statistical tests: the Kolmogorov-Smirnov test and Mann-Whitney $U$-test. A $p$ value of $<0.05$ was considered statistically significant.

\section{RESULTS}

There were a total of 39 patients (42 eyes), comprising 18 men and 21 women. The average age was 60 years (range 29-85 years). All 39 patients completed the study and results from 42 procedures have been obtained.

The perioperative IOP taken at both $t=0$ and $\mathrm{t}=5$ minutes ranged from 0 to $16 \mathrm{mmHg}$. The mean at $t=$ 0 was $5.1 \mathrm{mmHg}$ and at $t=5$ was $5.3 \mathrm{mmHg}$. In 24 cases there was no difference between the $t=0$ and $t$ $=5$ value, in 15 cases there was a difference of $1 \mathrm{mmHg}$ and in 3 cases there was a difference of $2 \mathrm{mmHg}$.

The mean IOP for the 42 cases increased over the following month from a mean perioperative IOP (i.e. the mean value of $t=0$ and $t=5$ ) of $5.2 \mathrm{mmHg}$ to $7.9 \mathrm{mmHg}$ at 1 day, to $9.7 \mathrm{mmg}$ at 1 week, and to $14.7 \mathrm{mmHg}$ at 1 month.

If the cases are classified on the basis of the value of the mean perioperative IOP then the sample can be divided into two groups. Group 1 comprises procedures where the mean perioperative IOP was $\leqslant 5 \mathrm{mmHg}$ ( 23 cases) and group 2 comprises procedures where the IOP was $>5 \mathrm{mmHg}$ (19 cases).

The mean IOP showed a steady increase in both groups to $13.5 \mathrm{mmHg}$ in group 1 and $16.3 \mathrm{mmHg}$ in

Table II. Mean (range) IOP levels $(\mathrm{mmHg})$ both perioperatively and at 1 month in groups $\mathrm{A}$ and $\mathrm{B}$

\begin{tabular}{lcc}
\hline & \multicolumn{2}{c}{ IOP (mmHg) } \\
\cline { 2 - 3 } & Perioperative & 1 month post-op. \\
\hline Group A (10 cases) & $1.7(0-12.5)$ & $13.2(6-18)$ \\
Group B (32 cases) & $6.3(2-16)$ & $15.2(6-30)$ \\
\hline
\end{tabular}

group 2 at 1 month. The mean values for IOP against time for both the entire sample of 42 cases and for groups 1 and 2 separately are summarised in Table I.

The IOP at 1 month in the sample as a whole and in both groups 1 and 2 tended to a value in the midteens. The difference in mean IOP at 1 month between groups 1 and 2 was $2.8 \mathrm{mmHg}$. This difference is not statistically significant $(p>0.05)$.

Five cases had an IOP greater than $21 \mathrm{mmHg}$ at 1 month (mean $24.4 \mathrm{mmHg}$, range $22-30 \mathrm{mmHg}$ ). These 5 patients were regarded as being at a higher risk for failure ( 2 repeat procedures, 1 case of angle closure and 2 in patients of Afro-Caribbean origin). The mean perioperative IOP of these 5 cases was $8.1 \mathrm{mmHg}$, which compares with $4.8 \mathrm{mmHg}$ for the other 37 cases where the 1 month IOP was less than $21 \mathrm{mmHg}(p>0.05)$.

There were no cases of flat ACs with corneal-lens touch (grade a shallowing), but 10 cases of flat ACs with iris-corneal touch (grade b) were seen. Eight of these cases were documented on the first postoperative day, although in these cases the iriscorneal touch resolved by 1 week. Two cases developed at 1 week and both resolved by 1 month. None of these 10 cases was found to have an aqueous leak. All other cases were graded as either grade $\mathrm{c}$ or $\mathrm{d}$, and all these cases were grade $\mathrm{d}$ by 1 month.

Analysis of the results on the basis of AC shallowing is simplified by dividing the patients into two groups. Group A comprises those 10 cases with grade $b$ shallowing occurring at any stage within the first post-operative week and we have defined these cases as having clinically significant AC shallowing. Group B are the remaining 32 cases, which had no greater than grade c AC shallowing at any stage.

The mean and range of IOPs both perioperatively and at 1 month for cases in groups $\mathrm{A}$ and $\mathrm{B}$ are shown in Table II. In group A the perioperative IOP ranged from 0 to $12.5 \mathrm{mmHg}$. Seven cases had a perioperative IOP of $0 \mathrm{mmHg} ; 1$ case each had a perioperative IOP of 1,3 and $12.5 \mathrm{mmHg}$, respectively. In group B the range was from 2 to $16 \mathrm{mmHg}$, with no case having a perioperative IOP of less than $2 \mathrm{mmHg}$.

The mean perioperative IOP was $1.7 \mathrm{mmHg}$ for cases in group $\mathrm{A}$ and $6.3 \mathrm{mmHg}$ in group $\mathrm{B}$, whilst the 1 month mean IOP was $13.2 \mathrm{mmHg}$ in group A and $15.2 \mathrm{mmHg}$ in group B. There is a statistically significant difference between the mean periopera- 
tive IOP in groups A and B $(p<0.01)$; however, at 1 month IOP this difference is not significant $(p>0.05)$.

\section{DISCUSSION}

A trabeculectomy is generally regarded as a success if the IOP is lowered to less than $21 \mathrm{mmHg}$, although in certain cases a pressure in the low teens (approximating to episcleral venous pressure) may be necessary. . $^{-9-11}$

The prognostic indicators influencing the longterm success of a trabeculectomy have been reviewed, indicating limited value of the early postoperative IOP as a predictor of the filtration state at 3 months. ${ }^{12}$ More recent work, however, suggests the early post-operative pressure has a higher accuracy for predicting long-term success and to a lesser extent failure. 13,14

This study looked only at the IOP within the first month, which whilst not a reflection of eventual surgical outcome is an important parameter in the post-operative management.

The results show that eyes with a wide range of perioperative IOPs developed a similar IOP in the mid-teens by 1 month. This has been suggested previously in a study comparing two techniques of trabeculectomy producing either high or low initial aqueous outflow, where there was no significant difference between post-operative IOP at 1 week in the two groups. ${ }^{15}$

Conversely the 5 cases with IOP $>21 \mathrm{mmHg}$ at 1 month showed no significant difference in their mean perioperative IOP when compared with the other 37 cases with a 1 month IOP $<21 \mathrm{mmHg}$. The small sample size, however, makes statistical conclusions difficult.

When considering IOP and AC depth, however, there is a significant difference between the mean perioperative IOP in groups $\mathrm{A}$ and $\mathrm{B}$, although this difference is not significant at 1 month. The cases with shallow ACs did not have conjunctival leaks on clinical examination and overdrainage appeared to be the mechanism of the hypotony. We cannot exclude the presence of a small intermittent leak contributing to the chamber shallowing, but overdrainage itself may be a factor in the development of leaking blebs by delaying the formation of a watertight fibrous seal at the edge of the bleb.

If flatter ACs are seen in eyes which are significantly softer perioperatively, we can try to obtain some idea of the sensitivity and specificity that the perioperative IOP had in predicting whether a patient would fall into group A or group B.

Table III shows the distribution of patients in groups $\mathrm{A}$ and $\mathrm{B}$ against the mean perioperative IOP of $3 \mathrm{mmHg}$. Cases in the two groups have been divided into those having an IOP either $\leqslant 3 \mathrm{mmHg}$ or alternatively $>3 \mathrm{mmHg}$. From this it can be seen that using this level of perioperative IOP there is $90 \%$ sensitivity and $88 \%$ specificity for detecting those patients who develop clinically significant chamber shallowing. The predictive value of a positive test is $9 / 13$, i.e. $70 \%$, whilst that of a negative test is $28 / 29$, i.e. $96 \%$.

If the level is changed to $2 \mathrm{mmHg}$ there is a slight decrease in sensitivity to $80 \%$ with an increase in specificity to $93 \%$. The predictive value of a positive test increases to $80 \%$ whilst for a negative test the predictive value decreases slightly to $94 \%$. At higher levels than $3 \mathrm{mmHg}$ there is a loss in specificity with a marked decrease in the predictive value of a positive test.

These figures clearly apply only under the conditions in this study and there are many variables which may influence the perioperative IOP. All operations here were performed with the patient under general anaesthetic and the injection of local anaesthetic around the globe will influence the IOP. In addition, although many surgeons routinely re-form the $\mathrm{AC}$ at the end of a trabeculectomy, the stage of the operation when this is done and the precise endpoint of re-formation varies between individual surgeons. In this study the $\mathrm{AC}$ was reformed prior to resuturing the conjunctiva, which has the advantage of allowing further modification to be made to the sutures in the scleral flap.

We feel, however, that some objective marker of IOP at the end of a trabeculectomy allows a reasonable prediction to be made as to whether the eye will develop significant post-operative AC shallowing. The perioperative measurement appears to be reproducible, with good similarity between the two readings, and suggests that only one measurement is required, taken immediately after re-forming the AC but before drawing up the conjunctival flap.

The perioperative IOP does not appear to be a useful predictor of the IOP 1 month after surgery. It may, however, have a role in predicting those eyes in which there is likely to be overdrainage of aqueous and AC shallowing. By correcting this it may therefore be possible to minimise subsequent com-

Table III. The distribution of cases in group A and B against a perioperative IOP of $3 \mathrm{mmHg}$. The sensitivity and specificity of this IOP in predicting the occurrence of clinically significant anterior chamber shallowing in the first post-operative week is shown, together with the predictive value of a positive and negative test

\begin{tabular}{|c|c|c|c|c|c|c|}
\hline Periop. IOP & Group A & Group B & Sensitivity & Specificity & $\begin{array}{l}+ \text { ve predictive } \\
\text { value }\end{array}$ & $\begin{array}{l}\text {-ve predictive } \\
\text { value }\end{array}$ \\
\hline $\begin{array}{l}\leqslant 3 \mathrm{mmHg} \\
>3 \mathrm{mmHg}\end{array}$ & $\begin{array}{l}9 \\
1\end{array}$ & $\begin{array}{r}4 \\
28\end{array}$ & 0.9 & 0.88 & 0.7 & 0.96 \\
\hline
\end{tabular}


plications and allow the surgeon to have a higher index of suspicion for these cases in the postoperative period.

Key words: Trabeculectomy, Perioperative intraocular pressure, Anterior chamber shallowing.

\section{REFERENCES}

1. Cairns JE. Trabeculectomy: preliminary report of a new method. Am J Ophthalmol 1968;66:673-9.

2. Watson PG. Trabeculectomy: a modified $a b$ externo technique. Ann Ophthalmol 1970;2:199-205.

3. Drake M. Complications of glaucoma filtration surgery. Int Ophthalmol Clin 1992;32:115-30.

4. Watson PG, Jakeman C, Ozturk M, Barnett MF, Barnett F, Khaw KT. The complications of trabeculectomy. Eye 1990;4:425-38.

5. Goins K, Smith T, Kinker R, Lewis J. Axial anterior chamber depth after trabeculectomy. Ophthalmologica 1990;200:177-80.

6. Kao SF, Lichter PR, Musch DC. Anterior chamber depth following filtration surgery. Ophthalmic Surg 1989;20:332-6.

7. Stewart WC, Shields MB. Management of anterior chamber depth after trabeculectomy. Am J Ophthalmol 1988;106:41-4.

8. Austin MW, Wishart PK. Reformation of the anterior chamber following trabeculectomy. Ophthalmic Surg 1993;24:461-6.

9. Katz LJ, Spaeth GL. Filtration surgery. In: Ritch R, Shields MB, Krupin K, editors. The glaucomas, vol. 1. St Louis: CV Mosby, 1989:653-96.

10. Mills KB. Trabeculectomy: a retrospective long term follow up of 444 cases. Br J Ophthalmol 1981;65:790-5.

11. Ridgway A. Trabeculectomy: a follow up study. Br J Ophthalmol 1974;58:680-6.

12. Stewart WC, Shields MB, Miller KN, Blasini M, Sutherland SE. Early postoperative prognostic indicators following trabeculectomy. Ophthalmic Surg 1991;22:23-6.

13. Downes SM, Mission GP, Jones HS, O'Neill EC. The predictive value of post-operative intraocular pressures following trabeculectomy. Eye 1994;8:394- 7.

14. Yablonski ME, Wood SE. Relationship between postoperative intraocular pressure and success of trabeculectomy. Invest Ophthalmol Vis Sci 1993;34:734.

15. Batterbury $M$, Wishart PK. Is high initial aqueous outflow of benefit in trabeculectomy? Eye 1993; 7:109-12. 